\title{
A evolução do sistema partidário brasileiro: número de partidos e votação no plano subnacional 1982-2006'
}

\author{
Denise Paiva Ferreira \\ Departamento de Ciências Sociais \\ Universidade Federal de Goiás \\ Carlos Marcos Batista \\ Instituto de Ciência Política \\ Universidade de Brasília \\ Max Stabile \\ Graduando em Ciência Política \\ Universidade de Brasília
}

\begin{abstract}
Resumo: O objetivo deste artigo é analisar o processo de implementação e desenvolvimento do sistema partidário. Para tanto, analisamos a oferta partidária no Brasil, nas diferentes unidades da federação, no período 1982-2006. Para essa análise serão consideradas as seguintes variáveis: idade dos partidos, número de partidos efetivos e a evolução da votação recebida pelos partidos nas eleições para Câmara Federal, Senado e Governador e Assembléias Legislativas Estaduais. Desse modo, será possível uma análise mais abrangente e comparada do desenvolvimento do sistema partidário brasileiro.
\end{abstract}

Palavras-chave: sistema partidário; eleições majoritárias e proporcionais; partidos nominais; número de partidos efetivos; representação.

Abstract: The article analyzes the process of implementation and development of the Brazilian party system. In order to do so we analyze the electoral offer in the Brazilian federation from 1982-2006. The following variables will be considered: parties age, effective number of parties (ENP), and votes for Senate, Low Camber, State Governor and State Level Assembly. These procedures allow us to have a broad panorama of the Brazilian party system as well as of its development throughout almost three decades.

Keywords: party system; majoritarian and proportional elections; nominal parties; effective number of parties; representation.

\footnotetext{
1 Este artigo é um dos produtos de dois projetos de pesquisa financiados pelo CNPq: Bases Socioeconômicas da Volatilidade Eleitoral no Brasil (Processo No 401912/2004-3) e Micro-fundamentos da volatilidade eleitoral no Brasil: o ponto de vista do eleitorado (Processo No 477136/2006-0).
} 


\section{Introdução}

O ano de 1980 pode ser identificado como o ponto de referência inicial do sistema multipartidário brasileiro. Data daquele ano o processo de criação de novos partidos, resultado da reforma partidária de 1979 (Lei n 6767), que pôs fim ao bipartidarismo vigente durante o regime autoritário. O retorno ao pluripartidarismo, por um lado, possibilitou a criação e organização de novos partidos, a emergência de um ambiente político mais competitivo e diversificado, portanto, mais condizente com o processo de transição política então em curso. Por outro, foi parte integrante da estratégia deliberada do regime autoritário de dividir a oposição então aglutinada no MDB. Esse último lograva capitanear o voto de faixas expressivas do eleitorado oposicionista desde meados dos anos setenta (LAMOUNIER, 1988, 1990; STEPAN, 1988; FERREIRA, 1990; KINZO e SILVA, 1996).

A dinâmica da relação entre governo e oposição faz parte das peculiaridades do regime autoritário brasileiro. Esse último criou novo sistema partidário, manteve o calendário eleitoral e o funcionamento do Congresso Nacional. Todavia, a maioria das eleições ocorreu sob um clima de restrições ou casuísmos. Após a reforma partidária de 1979, os partidos existentes antes do regime autoritário não se reorganizaram a exemplo do que ocorreu nos demais países do Cone Sul. No caso brasileiro, foi criado um sistema partidário totalmente novo (KINZO, 1988, 2001; FERREIRA, 1990; FLEISCHER, 1997).

A criação de novos partidos foi um desafio para o eleitorado, que se deparou com agremiações partidárias novas e às quais deveria adaptar-se. As exceções eram PMDB e PDS, herdeiros, respectivamente, do espólio político e eleitoral do MDB e da ARENA. Portanto, cabia aos eleitores não só buscar conhecer os novos partidos, mas distinguir as clivagens existentes entre os mesmos, seu perfil ideológico, programático e conhecer suas plataformas eleitorais.

As elites políticas, por sua vez, também estavam diante de alguns desafios, dentre eles, criar e estruturar novos partidos em todo território nacional, exigência da legislação partidária. E, além disso, adaptar-se ao recém-inaugurado panorama plural da competição política, buscar um diferencial que lhes conferisse um perfil programático ou ideológico, tornar o partido conhecido do eleitorado e, sobretudo, conquistar seu apoio. No âmbito desse processo, lideranças foram reintegradas à vida pública, beneficiadas pela anistia, e procuraram se restabelecer e conquistar seu espaço na disputa política. Além disso, novos atores políticos surgiram e entraram no mercado eleitoral (KRAUSE e PAIVA, 2002).

No decorrer de quase três décadas que nos distanciam de 1980, vários estudos sobre o sistema partidário e os partidos políticos brasileiros foram produzidos. A agenda de pesquisa relacionada ao tema é bastante diversificada e 
contempla, por exemplo, estudos acerca das tendências, padrões e dinâmica da competição interpartidária. Um conjunto de pesquisas têm se dedicado ao impacto da legislação e do sistema eleitoral sobre a competição político-partidária e sobre a formação de maiorias ou coalizões governantes. Outras análises têm privilegiado a arena governamental e as relações entre os poderes executivo e legislativo para examinar a configuração partidária brasileira.

A polêmica em torno da fragilidade atávica, sistêmica dos partidos, da fragmentação do sistema partidário e seus impactos sobre a dinâmica governamental pode não ter sido totalmente superada, mas substituída por análises que têm se dedicado a esquadrinhar de forma mais sistemática, e com base em pesquisas empíricas mais abrangentes, a atuação dos partidos políticos e do sistema partidário. Portanto, dispomos hoje de uma vasta produção acerca dos partidos em suas várias esferas de atuação e grande parte das pesquisas têm apontado para a consolidação do quadro partidário brasileiro a partir dos anos noventa (KINZO, 1993; NICOLAU, 1996; LIMA JR, 1997; MAINWARING, 1999; MENEGUELLO, 1998; LIMONGI e FIGUEIREDO, 1995, 1999; SANTOS, 2001; RODRIGUES, 2002; SCHMITT, 2000; MELO, 2004; CARREIRÃO e KINZO, 2004; BRAGA, 2006; BOHN e PAIVA, 2006, 2007; KINZO e BRAGA, 2007; SANTOS, 2008).

A exemplo dessa literatura, este artigo tem como foco de análise os partidos políticos brasileiros, e busca averiguar sua longevidade, verificando quantas e quais agremiações partidárias mantiveram-se na competição pela preferência do eleitorado ou deixaram de existir entre 1980 e 2006. Em seguida, tratamos do desenvolvimento da oferta eleitoral nas diferentes unidades da federação.

Para analisar esses aspectos, organizamos o artigo em três partes. $\mathrm{Na}$ primeira, identificamos, no período 1982-2006, os partidos que se mantiveram na arena eleitoral, sua longevidade e idade média. Em seguida, analisamos a dinâmica da competição partidária nas eleições majoritárias (governos estaduais e senados) e proporcionais (Câmara Federal e Assembléias Legislativas Estaduais) na arena subnacional. Para levar a cabo esse procedimento, usamos como indicador o Número Efetivo de Partidos (NEP). Na terceira parte, verificamos o grau de apoio e preferência partidária do eleitorado, a partir dos resultados de estudos de opinião pública. Por último, analisamos o padrão geral observado e suas implicações. 
FERREIRA, D. P., BATISTA, C. M., STABILE, M. A evolução do sistema partidário...

\section{1 - Oferta Partidária e Longevidade dos Partidos Políticos no Brasil 1982-2006}

As primeiras eleições da qual participaram os partidos criados após a reforma partidária de 1979 ocorreram em 1982. Esta competição eleitoral demarcou o retorno da disputa direta para os governos estaduais, suspensas desde 1966. Naquele ano, cinco partidos, criados em 1980, concorreram pela preferência do eleitorado: PDS, PMDB, PT, PDT e PTB (KINZO, 1993; NICOLAU, 1996; FERREIRA, 1990, 2002; MAINWARING, 1999; SCHMITT, 2000).

\section{Gráfico 1}

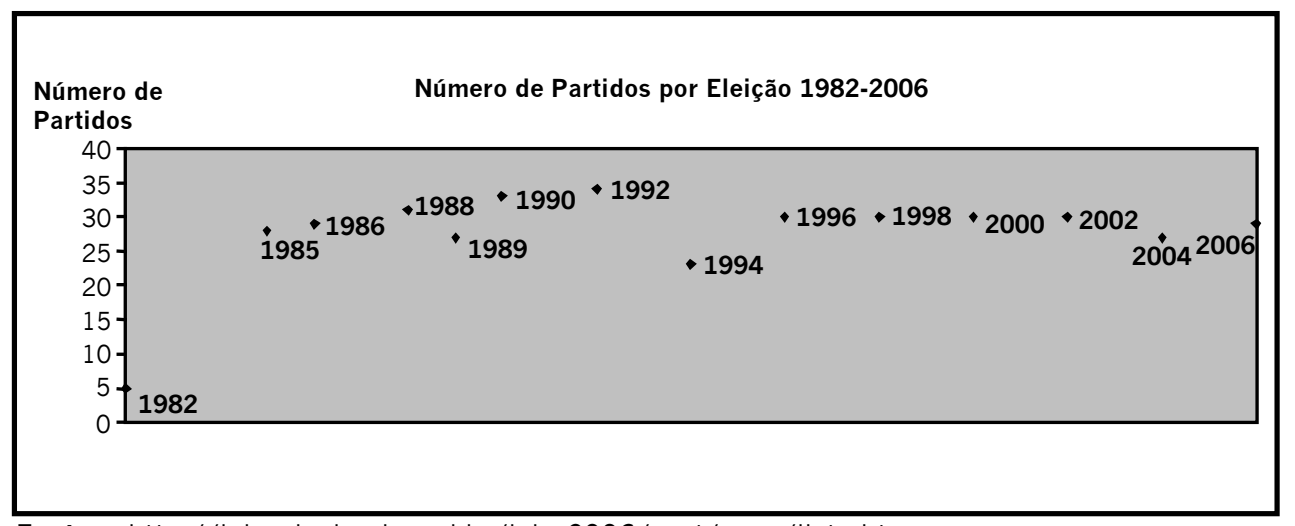

Fonte:< http://jaironicolau.iuperj.br/jairo2006/port/pags/lista.htm >

O Gráfico 1 permite visualizar a evolução da oferta partidária no período analisado por este estudo. Como se pode perceber, no decorrer de três anos (1982. 1985) houve um crescimento vertiginoso do número de partidos que concorreram às eleições, chegando a 460\%, sendo que, entre 1985 e 1988, foram registrados nada menos do que vinte e sete partidos no Tribunal Superior Eleitoral TSE, (Quadro 1). Em 1989, quando ocorreram as primeiras eleições presidenciais diretas desde 1960, houve um ligeiro declínio no número de competidores, possivelmente explicado pelo fato de tratar-se de uma eleição solteira e uma disputa cujo colégio eleitoral é todo o país. Desse modo, os muitos arranjos eleitorais que ocorrem nas vinte e sete unidades eleitorais nas eleições seguintes não estavam presentes. No entanto, não dispomos de dados que permitam confirmar essa hipótese.

Em 1990 e 1992 houve um crescimento da oferta partidária de 22\% e 30\%, respectivamente. Em 1994, por outro lado, observou-se uma diminuição considerável do número de competidores. É oportuno mencionar que, excluído o pleito de 1985, aquele foi o que teve o menor número de partidos nominais: vinte e três. A partir de 1996, iniciou-se uma tendência de estabilização do número de competidores (Gráfico 1). 
Em nosso entendimento esse boom na criação de novos partidos até o início dos anos noventa pode ser explicado, em grande parte, pelo hiperativismo das elites partidárias diante de um processo de rearranjo das forças políticas após a reforma de partidos. O processo de transição política é um elemento a ser agregado a essa explicação; nesse período, um novo cenário político e institucional estava sendo implementado no país, o que explica, pelo menos em parte, o realinhamento das várias forças políticas. Além disso, outros fatores, como uma legislação partidária e eleitoral permissiva, acabaram por incentivar a criação de novos partidos (NICOLAU, 1996; KRAUSE e PAIVA, 2002).

Nicolau (1996), ao analisar essa questão, chama atenção para os principais aspectos da legislação partidária que foram determinantes para o crescimento do número de partidos registrados no TSE a partir de 1985. O primeiro foi a Emenda Constitucional $\mathrm{n}^{\circ} 25$, de maio daquele ano, que facultou a organização de partidos cujos registros haviam sido cassados, indeferidos ou cancelados, permitindo a reorganização dos partidos comunistas (PCB e PCdoB). Porém, nessa esteira, vários micro-partidos fizeram o mesmo, o que contribuiu para inflacionar a oferta partidária no mercado eleitoral (Quadro $1^{2}$ ).

Outro aspecto determinante foi a permissão para que partidos em processo de formação, que não dispunham de registro definitivo no TSE, pudessem participar das eleições entre 1985 e 1992. Em 1994, houve um maior rigor na legislação eleitoral, que vetou a participação de partidos sem registro definitivo (NICOLAU, 1996; FLEISCHER, 1997; SCHMITT, 2000), o que acabou por diminuir o número de competidores (Gráfico 1). Ainda conforme Nicolau (1996), a legislação partidária no Brasil até 1995 caracterizou-se por ser bastante liberal no estabelecimento de regras para participação e ingresso no Congresso Nacional e acesso a recursos políticos. Em contrapartida, muito detalhista e criteriosa no que concerne à concessão do registro definitivo no TSE.

A partir de 1994, houve uma inflexão dessa tendência e a legislação passou a produzir menos incentivos para criação de novos partidos. Como forma de se antecipar a esse rigor, em 1993, ocorreram várias fusões (Quadro1). Porém, foi a Lei dos Partidos (Lei n9096, de setembro de 1995) que acabou por disciplinar de forma mais perene o processo de criação e funcionamento dos partidos políticos no Brasil. O Quadro 1 mostra claramente que a partir da sua promulgação houve um declínio do hiperativismo das elites partidárias e, conseqüentemente, a estabilização do número de competidores. Ao longo do período 1982-2006, a média é de 29,3 partidos nominais em cada eleição ${ }^{3}$.

\footnotetext{
${ }^{2}$ De acordo com o artigo sexto da referida emenda: "Os partidos políticos que, até a data desta Emenda, tenham tido seus registros indeferidos, cancelados ou cassados, poderão reorganizar-se, desde que atendidos os princípios estabelecidos no "caput" e itens do art. 152 da Constituição".

${ }^{3}$ De acordo com o TSE, o número de partidos registrados atualmente é vinte e sete. Essas informações estão disponíveis web site do TSE: <www.tse.gov.br>.
} 
Não obstante a explosão da oferta partidária, é importante reiterar que a maioria dessas legendas teve uma existência efêmera, sendo que a grande maioria não logrou obter o registro definitivo no TSE ou representação política (NICOLAU 1996; FLEISCHER, 1997; SCHMITT, 2000; KRAUSE e PAIVA, 2002). Poderíamos classificá-los como flash parties, expressão cunhada por Rose e Mackie (1988) para classificar os partidos que não causam impacto na e/ou têm uma existência efêmera ou meteórica. Nicolau (1996) também chama atenção para essa questão bem como aponta para a existência de partidos criados por cidadãos anônimos e sem prévias atividades relevantes no cenário político.

\section{Quadro 1 - Partidos Políticos Brasileiros 1980-2008}

\begin{tabular}{|c|c|c|}
\hline Sigla & Nome & $\begin{array}{c}\text { Ano de } \\
\text { fundação e } \\
\text { extinção }^{4}\end{array}$ \\
\hline PDT & Partido Democrático Trabalhista & 1980 \\
\hline PMDB & Partido do Movimento Democrático Brasileiro & 1980 - \\
\hline PT & Partido dos Trabalhadores & 1980. \\
\hline PTB & Partido Trabalhista Brasileiro & 1980 . \\
\hline $\begin{array}{l}\text { PDS/PPR/ } \\
\text { PPB/PP }^{5}\end{array}$ & $\begin{array}{c}\text { Partido Democrático Social/ Partido Progressista } \\
\text { Reformador/ Partido Progressista } \\
\text { Brasileiro/Partido Progressista }\end{array}$ & $\begin{array}{r}1980 / 1993 / \\
1995 / 2003\end{array}$ \\
\hline $\mathbf{P P}^{6}$ & Partido Popular & $1980 \cdot 1981$ \\
\hline PCN & Partido Comunitário Nacional & $1982 \cdot 1992$ \\
\hline PN & Partido Nacionalista & 1985 \\
\hline PNR & Partido da Nova República & 1985 \\
\hline PTN & Partido Tancredista Nacional & 1985 \\
\hline PCdoB & Partido Comunista do Brasil & 1985. \\
\hline PFL/DEM $^{7}$ & Partido da Frente Liberal & 1985 . \\
\hline PSB & Partido Socialista Brasileiro & 1985 . \\
\hline PSC & Partido Social Cristão & 1985 \\
\hline PJ/PRN/PTC 8 & $\begin{array}{c}\text { Partido da Juventude/ Partido da Reconstrução } \\
\text { Nacional/Partido Trabalhista Cristão }\end{array}$ & $\begin{array}{l}1985 / 1989 / \\
2001\end{array}$ \\
\hline 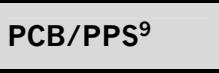 & $\begin{array}{l}\text { Partido Comunista Brasileiro/ Partido Popular } \\
\text { Socialista }\end{array}$ & $1985 / 1992$ \\
\hline
\end{tabular}

\footnotetext{
${ }^{4}$ A informação sobre o ano de fundação dos partidos se refere ao pedido de registro provisório no Tribunal Superior Eleitoral (TSE).

${ }^{5}$ O PDS fundiu-se com o PDC em 1993, passando a chamar-se Partido Progressista Reformista (PPR). 0 PPR fundiu-se com o PP em 1995, passando-se a chamar Partido Progressista Brasileiro (PPB). A partir da Convenção Nacional realizada em abril de 2003, PPB retirou a letra B de sua sigla passando a se chamar PP (Partido Progressista).

${ }^{6}$ O Partido Progressista foi criado após a reforma partidária de 1979 e aglutinava integrantes da Arena e do MDB, sua principal liderança foi Tancredo Neves. O partido foi incorporado ao PMDB em 1981.

${ }^{7}$ A partir de março de 2007, alterou o nome para Democratas.

8 Passou a se chamar Partido da Reconstrução Nacional (PRN) em 1989. Em 2000, passa a se chamar Partido Trabalhista Cristão (PTC).

${ }_{9}^{9}$ Passou a se chamar Partido Popular Socialista (PPS) em 1992.
} 
OPINIÃO PÚBLICA, Campinas, vol. 14, n², Novembro, 2008, p.432-453

\begin{tabular}{|c|c|c|}
\hline Sigla & Nome & $\begin{array}{c}\text { Ano de } \\
\text { fundação e } \\
\text { extinçãa } 0^{10}\end{array}$ \\
\hline$\overline{P D I}$ & Partido Democrático Independente & $1985 \cdot 1986$ \\
\hline PRT & Partido Reformador Trabalhista & 1985.1986 \\
\hline$\overline{\mathrm{PH}}$ & Partido Humanista & $1985 \cdot 1987$ \\
\hline PASART & Partido Agrário Renovador Trabalhista & $1985 \cdot 1988$ \\
\hline PMB & Partido Municipalista Brasileiro & 1985.1990 \\
\hline PDC & Partido Democrata Cristão & 1985.1993 \\
\hline PTR $^{11}$ & Partido Trabalhista Renovador & 1985.1993 \\
\hline$\overline{\mathrm{PL}}$ & Partido Liberal & $1985 \cdot 2006^{12}$ \\
\hline PMC & Partido Municipalista Comunitário & $1985 \cdot 1986$ \\
\hline PND & Partido Nacionalista Democrático & 1985.1986 \\
\hline$\overline{\text { PS }}$ & Partido Socialista & 198519.89 \\
\hline PSD $^{13}$ & Partido Social Democrático & 1987.2002 \\
\hline$\overline{P L P}$ & Partido Liberal Progressista & 1988 \\
\hline PSDB & Partido da Social Democracia Brasileira & 1988 . \\
\hline$\overline{\mathrm{PHN}}$ & Partido Humanista Nacional & 1988.1989 \\
\hline$\overline{\text { PNA }}$ & Partido Nacional dos Aposentados & 1988.1989 \\
\hline PNAB & Partido Nacional dos Aposentados do Brasil & 1988.1989 \\
\hline$\overline{\text { PAS }}$ & Partido de Ação Social & 1988.1989 \\
\hline PDN & Partido Democrático Nacional & 1989 \\
\hline$\overline{P P}$ & Partido do Povo & 1989 \\
\hline$\overline{\text { PPB }}$ & Partido do Povo Brasileiro & 1989 \\
\hline PRP & Partido Republicano Progressista & 1989 \\
\hline$\overline{\text { PSP }}$ & Partido Social Progressista & 1989 \\
\hline PDCdoB & Partido Democrata Cristão do Brasil & 1989 \\
\hline PMN & Partido da Mobilização Nacional & 1989. \\
\hline$\overline{\text { PST }}$ & Partido Social Trabalhista & $1989 \cdot 1993$ \\
\hline PRONA & Partido de Reedificação da Ordem Nacional & $1989 \cdot 2006^{14}$ \\
\hline PD & Partido Democrata & 1989.1991 \\
\hline PAP & Partido de Ação Progressista & 1990 \\
\hline PBM & Partido Brasileiro de Mulheres & 1990 \\
\hline PEB & Partido Estudantil Brasileiro & 1990 \\
\hline PLH & Partido Liberal Humanista & 1990 \\
\hline PRS & Partido das Reformas Sociais & 1990 \\
\hline PSL & Partido do Solidarismo Libertador & 1990 \\
\hline PSU & Partido Socialista Unido & 1990 \\
\hline PV & Partido Verde & 1990. \\
\hline$\overline{\text { PNT }}$ & Partido Nacionalista dos Trabalhadores & 1990-1991 \\
\hline PCDN & Partido Cívico de Desenvolvimento Nacional & 1990-1992 \\
\hline PTdoB & Partido Trabalhista do Brasil & 1991. \\
\hline PSdoB & Partido Socialista do Brasil & 1991.1992 \\
\hline
\end{tabular}

10 A informação sobre 0 ano de fundação dos partidos se refere ao pedido de registro provisório no Tribunal Superior Eleitoral (TSE).

11 O PTR fundiu-se com o PST em 1993, passando a se chamar Partido Progressista.

12 O PL fundiu-se ao PRONA em 2006 formando o Partido da República.

13 O PSD foi incorporado ao PTB em 2002.

14 O PRONA fundiu-se ao PL em 2006 formando o Partido da República. 
FERREIRA, D. P., BATISTA, C. M., STABILE, M. A evolução do sistema partidário...

\begin{tabular}{|c|c|c|}
\hline Sigla & Nome & $\begin{array}{c}\text { Ano de } \\
\text { fundação e } \\
\text { extinção }^{15}\end{array}$ \\
\hline PLT & Partido Liberal Progressista & $1991 \cdot 1993$ \\
\hline PFS & Partido da Frente Socialista & 1992 \\
\hline PLB & Partido Liberal Brasileiro & 1992 \\
\hline PNTB & Partido Nacionalista dos Trabalhadores do Brasil & 1992 \\
\hline PPN & Partido Parlamentarista Nacional & 1992 \\
\hline PTC & Partido Trabalhista Comunitário & 1992 \\
\hline PSTU & Partido Socialista dos Trabalhadores Unificado & 1992. \\
\hline PMSD & Partido Municipalista Social Democrático & $1992 \cdot 1993$ \\
\hline PES & Partido Ecológico Social & 1992-1994 \\
\hline PLC & Partido Liberal Cristão & $1992 \cdot 1993$ \\
\hline PTRB & Partido Trabalhista Renovador Brasileiro & 1993 \\
\hline PCB $^{16}$ & Partido Comunista Brasileiro & 1993. \\
\hline PSN/PHS ${ }^{17}$ & $\begin{array}{l}\text { Partido Solidarista Nacional/Partido Humanista } \\
\text { da Solidariedade }\end{array}$ & 1993 \\
\hline $\mathbf{P P}^{18}$ & Partido Progressista & 1993.1995 \\
\hline $\mathrm{PGT}^{19}$ & Partido Geral dos Trabalhadores & $1993 \cdot 2003$ \\
\hline PSL & Partido Social Liberal & 1994- \\
\hline PCO & Partido da Causa Operária & 1995. \\
\hline PRTB & Partido Renovador Trabalhista Brasileiro & 1995 \\
\hline PSDC & Partido Social Democrata Cristão & 1995. \\
\hline PTN & Partido Trabalhista Nacional & 1995. \\
\hline $\mathrm{PAN}^{20}$ & Partidos dos Aposentados da Nação & $1995-2007$ \\
\hline $\mathrm{PST}^{21}$ & Partido Social Trabalhista & 1996 \\
\hline PRB & Partido Republicano Brasileiro & 2005. \\
\hline PSOL & Partido do Socialismo e Liberdade & 2005 \\
\hline $\mathrm{PR}^{22}$ & Partido da República & 2006 . \\
\hline
\end{tabular}

Fonte: Nicolau, J. M. Dados eleitorais no Brasil, disponível em: <http://www.iuperj.br/deb/port/Indice.htm> e Tribunal Superior Eleitoral (TSE) . Seção de Registros de Partidos Políticos.

Como mostra o Quadro 1, a lista de partidos ao longo de quase três décadas é muito extensa. Também se destaca o grande número de cisões e fusões partidárias ocorridas no período. As fusões muitas vezes facultaram aos micro ou pequenos partidos uma sobrevida. A taxa de longevidade ou idade média dos partidos extintos, no período 1980-2006, é de 2,7 anos. Portanto, a maior parte

\footnotetext{
15 A informação sobre o ano de fundação dos partidos se refere ao pedido de registro provisório no Tribunal Superior Eleitoral (TSE).

16 O PCB foi recriado em 1993.

17 Em 1997, o PSN passou a chamar-se Partido Humanista da Solidariedade (PHS).

18 O PP foi fundado em 1993 a partir da fusão entre PTR e PST. Em 1995, foi incorporado ao PPR originando o PPB.

19 O PGT foi incorporado ao PL em 2003.

20 O PAN foi incorporado ao PTB em 2007, conforme resolução n. 22.519/2007 do TSE.

21 O PST foi recriado em 1996 e incorporado ao PL em 2003.

22 O PR foi fundado a partir da fusão do PL e PRONA.
} 
desses partidos não participou de mais de dois pleitos consecutivos. Já os partidos que atualmente participam da competição eleitoral têm uma idade média de 17,8 anos (BOHN e PAIVA, 2006) ${ }^{23}$. Cabe destacar que os partidos mais longevos são exatamente aqueles que foram criados em 1980, isto é: PMDB, PT, PDT, PTB e $\mathrm{PP}^{24}$. Além disso, esses partidos têm alcançado maior êxito na competição eleitoral. PSDB e DEM, por sua vez, também estão na lista dos partidos bem sucedidos quanto aos resultados obtidos nas urnas, não obstante terem sido criados, respectivamente, em 1985 e 1988 (portanto, um pouco mais jovens). Porém estes resultaram de cisões ocorridas no $\mathrm{PMDB}$ e no antigo $\mathrm{PDS}$, atual $\mathrm{PP}^{25}$ e, desse modo, com sua linhagem vinculada àquelas agremiações (KINZO, 1993; NICOLAU, 1996; KINZO e SILVA, 1996; FLEISCHER, 1997; MAINWARING, 1999; FERREIRA, 1990, 2002; KRAUSE e PAIVA, 2002).

Alguns estudos apontam que a longevidade, definida como a maior permanência na arena eleitoral, é um indicador de que os partidos políticos têm conseguido obter um apoio estável e construir laços de lealdade entre setores do eleitorado (MAINWARING e SCULLY, 1995; MAINWARING, 1999; KINZO e BRAGA, 2007). Esta questão está examinada no final deste artigo.

Tomando os estados da federação como unidades de análise, constatamos que o padrão observado no Gráfico 1 mantém-se, isto é, um número considerável de partidos concorrendo a cada eleição. Porém, padrões distintos são observados em cada unidade. Algumas delas - como Distrito Federal, Minas Gerais, Paraná, Pernambuco, Rio de Janeiro e São Paulo - apresentam sistematicamente médias superiores às demais. Já os estados do Acre, Piauí, Rio Grande do Norte, Mato Grosso do Sul e Tocantins apresentam médias menores em algumas das eleições.

Tais diferenças podem ser explicadas pela configuração da disputa entre as elites regionais e o maior ou menor grau de competitividade das mesmas. Por conseguinte, se há maior concorrência entre as elites, esta traduzir-se-á em um número maior de competidores na arena eleitoral. Outro elemento a ser agregado à explicação é o tamanho do colégio eleitoral: os estados com maior número de competidores estão entre aqueles com maior número de eleitores, com exceção do Distrito Federal. Por outro lado, os estados com as menores médias figuram entre aqueles com menor número de eleitores, particularmente Acre e Tocantins.

\footnotetext{
23 Numa comparação dos partidos políticos na América Latina em termos de longevidade as agremiações partidárias brasileiras ocupam o último lugar, sendo, portanto, as mais jovens MAINWARING e SCULLY, 1995.

24 Dos partidos mencionados, o atual PP foi o que mais sofreu mutações.

25 DEM e PSDB foram criados por dissidentes do PDS e PMDB, respectivamente, (KINZO, 1993; FERREIRA, 2002).
} 
FERREIRA, D. P., BATISTA, C. M., STABILE, M. A evolução do sistema partidário...

Bardi e Mair (2008) chamam atenção para a existência de divisões horizontais dentro de um mesmo sistema partidário. Essas divisões são observáveis principalmente em sistemas políticos descentralizados e nos quais há diferentes níveis de governo, como é o caso de países que, como o Brasil, adotam o federalismo como modelo de organização política. Esse formato institucional acaba por criar incentivos para que estados ou regiões desenvolvam uma dinâmica própria de competição que pode levar à existência de subsistemas partidários ou diferentes padrões de competição nos estados, como se observa na Tabela 1 (LIMA JR, 1983, 1997; FERREIRA, 2002).

A Tabela 1 também mostra uma nítida diferença no número de partidos nominais entre eleições proporcionais (Câmara de Deputados e Assembléias Legislativas) e majoritárias (Governador e Senado), o que pode ser explicado pela diferença de regras e arranjos institucionais nos dois tipos de pleitos, que imprimem diferentes formatos à competição partidária. Assim, Kinzo e Braga (2007), ao analisarem a competição partidária nos legislativos estaduais, chamam atenção para esse aspecto.

Tabela 1 - Número Médio de Partidos por Eleição, 1982-2006

\begin{tabular}{|c|c|c|c|c|c|c|c|}
\hline \multicolumn{2}{|c|}{ Câmara de Deputados } & \multicolumn{2}{|c|}{$\begin{array}{c}\text { Assembléias } \\
\text { Legislativas }\end{array}$} & \multicolumn{2}{c|}{ Governador } & \multicolumn{2}{c|}{ Senado } \\
\hline Estado & Média & Estado & Média & Estado & Média & Estado & Média \\
\hline Acre & 13,14 & Acre & 14,14 & Acre & 5,17 & Acre & 4,67 \\
\hline Alagoas & 17,57 & Alagoas & 18,57 & Alagoas & 5,67 & Alagoas & 7,00 \\
\hline Amapá & 16,00 & Amapá & 22,20 & Amapá & 5,67 & Amapá & 6,67 \\
\hline Amazonas & 18,14 & Amazonas & 19,14 & Amazonas & 6,33 & Amazonas & 6,00 \\
\hline Bahia & 18,14 & Bahia & 19,00 & Bahia & 7,17 & Bahia & 6,00 \\
\hline Ceará & 18,14 & Ceará & 18,29 & Ceará & 6,50 & Ceará & 6,67 \\
\hline $\begin{array}{c}\text { Distrito } \\
\text { Federal }\end{array}$ & 25,67 & $\begin{array}{c}\text { Distrito } \\
\text { Federal }\end{array}$ & 27,20 & $\begin{array}{c}\text { Distrito } \\
\text { Federal }\end{array}$ & 8,67 & $\begin{array}{c}\text { Distrito } \\
\text { Federal }\end{array}$ & 9,33 \\
\hline $\begin{array}{c}\text { Espírito } \\
\text { Santo }\end{array}$ & 18,00 & $\begin{array}{c}\text { Espírito } \\
\text { Santo }\end{array}$ & 19,00 & $\begin{array}{c}\text { Espírito } \\
\text { Santo }\end{array}$ & 5,83 & $\begin{array}{c}\text { Espírito } \\
\text { Santo }\end{array}$ & 7,00 \\
\hline Goiás & 18,00 & Goiás & 19,71 & Goiás & 6,67 & Goiás & 7,00 \\
\hline M. G. do Sul & 17,14 & M. G. do Sul & 17,86 & M. G. do Sul & 4,67 & M. G. do Sul & 6,00 \\
\hline Maranhão & 18,57 & Maranhão & 19,14 & Maranhão & 5,67 & Maranhão & 5,67 \\
\hline Mato Grosso & 18,14 & Mato Grosso & 17,14 & Mato Grosso & 6,33 & Mato Grosso & 5,67 \\
\hline $\begin{array}{c}\text { Minas } \\
\text { Gerais }\end{array}$ & 20,71 & $\begin{array}{c}\text { Minas } \\
\text { Gerais }\end{array}$ & 20,86 & $\begin{array}{c}\text { Minas } \\
\text { Gerais }\end{array}$ & 8,33 & $\begin{array}{c}\text { Minas } \\
\text { Gerais }\end{array}$ & 11,67 \\
\hline Pará & 17,71 & Pará & 17,86 & Pará & 583 & Pará & 8,00 \\
\hline
\end{tabular}


OPINIÃO PÚBLICA, Campinas, vol. 14, n², Novembro, 2008, p.432-453

\begin{tabular}{|c|c|c|c|c|c|c|c|}
\hline Câmara de Deputados & \multicolumn{2}{|c|}{$\begin{array}{c}\text { Assembléias } \\
\text { Legislativas }\end{array}$} & \multicolumn{2}{c|}{ Governador } & \multicolumn{2}{c|}{ Senado } \\
\hline Estado & Média & Estado & Média & Estado & Média & Estado & Média \\
\hline Paraíba & 17,00 & Paraíba & 18,00 & Paraíba & 5,83 & Paraíba & 6,33 \\
\hline Paraná & 20,14 & Paraná & 20,71 & Paraná & 9,17 & Paraná & 10,00 \\
\hline Pernambuco & 20,86 & Pernambuco & 20,86 & Pernambuco & 8,17 & Pernambuco & 8,33 \\
\hline Piauí & 15,57 & Piauí & 16,00 & Piauí & 5,83 & Piauí & 7,67 \\
\hline $\begin{array}{c}\text { R. G. do } \\
\text { Norte }\end{array}$ & 15,71 & $\begin{array}{c}\text { R. G. do } \\
\text { Norte }\end{array}$ & 16,86 & $\begin{array}{c}\text { R. G. do } \\
\text { Norte }\end{array}$ & 5,50 & $\begin{array}{c}\text { R. G. do } \\
\text { Norte }\end{array}$ & 5,67 \\
\hline R. G. do Sul & 16,43 & R. G. do Sul & 16,43 & R. G. do Sul & 8,00 & R. G. do Sul & 10,33 \\
\hline $\begin{array}{c}\text { Rio de } \\
\text { Janeiro }\end{array}$ & 24,14 & $\begin{array}{c}\text { Rio de } \\
\text { Janeiro }\end{array}$ & 24,00 & $\begin{array}{c}\text { Rio de } \\
\text { Janeiro }\end{array}$ & 12,17 & $\begin{array}{c}\text { Rio de } \\
\text { Janeiro }\end{array}$ & 13,67 \\
\hline Rondônia & 16,57 & Rondônia & 18,14 & Roraima & 6 & Rondônia & 11,00 \\
\hline Roraima & 16,29 & Roraima & 22,20 & Rondônia & 7 & Roraima & 7,33 \\
\hline $\begin{array}{c}\text { Santa } \\
\text { Catarina }\end{array}$ & 17,43 & $\begin{array}{c}\text { Santa } \\
\text { Catarina }\end{array}$ & 17,00 & $\begin{array}{c}\text { Santa } \\
\text { Catarina }\end{array}$ & 6,50 & $\begin{array}{c}\text { Santa } \\
\text { Catarina }\end{array}$ & 7,33 \\
\hline São Paulo & 22,00 & São Paulo & 21,86 & São Paulo & 12,00 & São Paulo & 15,33 \\
\hline Sergipe & 17,29 & Sergipe & 18,29 & Sergipe & 5,50 & Sergipe & 7,00 \\
\hline Tocantins & 18,80 & Tocantins & 21,00 & Tocantins & 4,4 & Tocantins & 5,33 \\
\hline
\end{tabular}

Fonte: Bohn \& Paiva, 2006.

\section{2 - Partidos e Competição Eleitoral nos Estados}

Em que medida a explosão da oferta partidária resultou em um número significativo de partidos relevantes? Esse é um aspecto importante, pois permite analisar melhor a dinâmica da competição eleitoral e o desempenho dos partidos. Para responder a essa pergunta, analisamos o número de partidos efetivos (NEP) desenvolvido por Laakso e Taagepera (1979).

Esse indicador nos permite ir além do número de partidos nominais, o qual não possibilita mensurar quantos partidos, efetivamente, têm peso nas eleições e exercem impacto no mercado eleitoral. Por conseguinte, o NEP nos faculta uma visão mais acurada acerca da dinâmica da competição partidária. Por último, torna possível calcular o número de partidos existentes em um determinado sistema partidário a partir de seu tamanho e relevância. No caso brasileiro, onde o número de partidos nominais é bastante alto, é fundamental fazermos essa distinção. 
FERREIRA, D. P., BATISTA, C. M., STABILE, M. A evolução do sistema partidário...

Tabela 2 - Número Efetivo de Partidos por Eleição por Estado, 1982-2006

\begin{tabular}{|c|c|c|c|c|c|c|c|c|c|c|c|c|c|c|}
\hline & \multicolumn{7}{|c|}{ Assembléias Legislativas Estaduais } & \multicolumn{7}{|c|}{ Câmara de deputados } \\
\hline & 1982 & 1986 & 1990 & 1994 & 1998 & 2002 & 2006 & 1982 & 1986 & 1990 & 1994 & 1998 & 2002 & 2006 \\
\hline RO & 2,05 & 3,43 & 6,98 & 11,9 & 8,96 & 11,84 & 13,22 & 2,06 & 2,74 & 5,57 & 7,09 & 7,12 & 7,76 & 7,29 \\
\hline AC & 2,41 & 2,73 & 4,37 & 5,39 & 7,49 & 9,29 & 9,83 & 2,42 & 2,3 & 4,38 & 3,39 & 4,51 & 7,64 & 7,85 \\
\hline AM & 2,09 & 3,99 & 7,23 & 7,9 & 8,26 & 12,15 & 13,62 & 2,09 & 4,04 & 7,3 & 5,3 & 4,39 & 5,04 & 9,26 \\
\hline RR & & & 8,15 & 6,22 & 7,67 & 16,93 & 15,71 & 1,64 & 3,06 & 6,14 & 3,84 & 4,12 & 6,53 & 11,4 \\
\hline PA & 2,09 & 3,0 & 8,26 & 6,34 & 9,03 & 8,8 & 9,1 & 2,09 & 2,37 & 6,18 & 4,56 & 6,74 & 6,13 & 6,52 \\
\hline AP & & & 8,11 & 7,14 & 10,1 & 11,61 & 14,42 & 1,51 & 2,99 & 6,31 & 5,88 & 8,53 & 8,83 & 8,38 \\
\hline TO & & & 5,05 & 4,05 & 4,37 & 6,73 & 8,48 & & & 4,21 & 4,1 & 3,47 & 5,13 & 5,68 \\
\hline MA & 1,52 & 3,46 & 5,96 & 9,04 & 11,13 & 6,86 & 10,01 & 1,53 & 2,8 & 4,87 & 5,27 & 6,62 & 6,47 & 8,87 \\
\hline PI & 1,91 & 2,7 & 4,61 & 4,03 & 4,96 & 6,28 & 8,66 & 1,92 & 2,78 & 4,74 & 4,43 & 3,95 & 4,99 & 7,63 \\
\hline CE & 1,64 & 3,04 & 6,33 & 4,94 & 5,19 & 7,64 & 7,08 & 1,64 & 3,09 & 5,9 & 3,51 & 3,86 & 5,77 & 6,47 \\
\hline RN & 1,93 & 3,11 & 4,63 & 4,95 & 6,05 & 7,92 & 8,75 & 1,94 & 2,9 & 4,98 & 3,54 & 4,27 & 5,65 & 7,62 \\
\hline PB & 1,93 & 3,14 & 4,92 & 3,72 & 3,76 & 6,49 & 6,8 & 1,94 & 2,48 & 4,97 & 3,18 & 4,32 & 7,19 & 6,42 \\
\hline PE & 1,99 & 3,63 & 7,02 & 5,2 & 7,39 & 11,9 & 12,25 & 2,01 & 2,58 & 4,06 & 3,92 & 5,85 & 7,92 & 9,59 \\
\hline$A L$ & 1,92 & 4,09 & 8,97 & 7,83 & 8,35 & 9,38 & 5,63 & 1,92 & 2,8 & 4,62 & 8,19 & 9,45 & 8,72 & 10,24 \\
\hline SE & 1,55 & 3,66 & 6,01 & 6,65 & 8,03 & 10,64 & 8,27 & 1,57 & 3,04 & 4,81 & 7,04 & 8,3 & 10,06 & 7,63 \\
\hline BA & 1,89 & 2,72 & 6,32 & 7,55 & 6,2 & 8,56 & 8,43 & 1,89 & 2,53 & 6,95 & 5,73 & 3,77 & 4,36 & 5,58 \\
\hline MG & 2,09 & 3,26 & 9,84 & 9,7 & 10,4 & 10,12 & 10,11 & 2,09 & 2,41 & 8,71 & 7,27 & 7,2 & 8,57 & 10,37 \\
\hline ES & 2,01 & 3,28 & 10,42 & 9,65 & 9,63 & 13,11 & 12,74 & 2,0 & 2,31 & 5,98 & 5,96 & 6,41 & 9,81 & 6,95 \\
\hline RJ & 3,77 & 7,41 & 7,98 & 10,29 & 8,77 & 11,2 & 11,28 & 3,74 & 6,25 & 5,57 & 9,78 & 8,29 & 11,25 & 12,83 \\
\hline SP & 2,95 & 4,56 & 8,39 & 7,19 & 8,82 & 8,33 & 7,95 & 2,96 & 4,11 & 7,99 & 6,69 & 7,73 & 7,99 & 8,93 \\
\hline PR & 2,01 & 2,35 & 6,94 & 6,98 & 7,09 & 9,87 & 7,21 & 2,0 & 2,01 & 6,47 & 7,83 & 6,96 & 8,16 & 7,92 \\
\hline SC & 2,03 & 3,23 & 5,76 & 5,4 & 5,41 & 5,97 & 6,19 & 2,03 & 3,02 & 5,13 & 4,9 & 5,53 & 5,63 & 6,23 \\
\hline RS & 2,91 & 3,35 & 6,31 & 5,98 & 6,3 & 7,51 & 8,25 & 2,91 & 3,17 & 5,26 & 5,79 & 5,9 & 6,87 & 8,50 \\
\hline MS & 2,08 & 3,28 & 6,93 & 7,02 & 6,96 & 10,47 & 7,2 & 2,07 & 3,12 & 5,4 & 5,09 & 6,1 & 6,19 & 5,56 \\
\hline MT & 2,01 & 3,15 & 5,89 & 8,46 & 7,22 & 8,31 & 7,26 & 2,01 & 2,32 & 5,99 & 6,94 & 4,6 & 6,45 & 8,05 \\
\hline GO & 1,84 & 2,62 & 5,07 & 7,4 & 5,41 & 7,81 & 7,5 & 1,84 & 2,25 & 3,91 & 4,84 & 3,99 & 5,69 & 6,57 \\
\hline DF & & & 12,11 & 6,26 & 10,14 & 10,34 & 11,44 & & 6,07 & 7,57 & 5,04 & 6,91 & 4,54 & 6,92 \\
\hline
\end{tabular}

Fonte: Bohn \& Paiva, 2006. 
As Tabelas 2 e 3 evidenciam que em 1982 houve um padrão bipartidário na competição eleitoral. Os dados também revelam que Arena e MDB, as agremiações vigentes durante o regime autoritário, balizaram a disputa por meio de sua nova roupagem, respectivamente PDS e PMDB. Outra explicação para esse resultado foram as restrições determinadas pela Lei n6978, conhecida como Pacote de Novembro, que, buscando fortalecer o PDS, partido governista, acabou por imprimir uma dinâmica bipartidária às eleições (LAMOUNIER,1988; FERREIRA, 1990, 2002; SCHMITT, 2000).

Em relação às eleições proporcionais, a Tabela 2 mostra que, em 1986, em que pese a explosão da oferta partidária discutida na seção anterior, não houve um aumento expressivo do número de partidos relevantes. Apenas o Rio de Janeiro fugiu ao padrão dos demais estados da federação na disputa para o legislativo estadual. A partir de 1990, o realinhamento partidário iniciou-se de forma mais acentuada em todos os estados e a tendência observada se manteve nos pleitos posteriores.

Por conseguinte, o número de partidos efetivos se ampliou ficando em torno de sete, bem abaixo do número de partidos nominais. Em estados como Rondônia, Amapá e Roraima, o NEP atingiu patamares bastante elevados nas eleições para as Assembléias Legislativas Estaduais. O caso de Roraima é interessante e merece maiores investigações.

Na Câmara de Deputados, embora o realinhamento partidário também tenha se revelado mais acentuado a partir de 1990, o número de partidos efetivos foi menor, cinco em média. É interessante observar que a variação do NEP entre os estados é menor do que aquela verificada nas eleições para o legislativo estadual, diferença explicada pelo impacto das regras eleitorais que aumentam os custos para o acesso às cadeiras no legislativo federal e os tornam mais acessíveis no plano regional, basicamente devido à relação entre o quociente eleitoral e a magnitude do distrito. Esse fator é destacado por Kinzo e Braga (2007) ao analisarem a estrutura da competição eleitoral nos legislativos estaduais.

As dinâmicas de realinhamento eleitoral e competição partidária nas eleições majoritárias podem ser observadas na Tabela 3. Como se pode verificar, o número de competidores relevantes é menor quando comparado com a disputa por cargos no legislativo. Nas eleições para o senado, nota-se uma competição mais plural, uma vez que em um número maior de estados o NEP fica em torno de 4, chegando a ser superior a 6, como ocorre em Roraima, Amapá, Sergipe, Rio de Janeiro em Minas Gerais. Para os governos estaduais o padrão é mais homogêneo: em geral, os partidos relevantes estão entre 2 e 3 . 
FERREIRA, D. P., BATISTA, C. M., STABILE, M. A evolução do sistema partidário...

Tabela 3 - Número Efetivo de Partidos por Eleição por Estado, 1982-2006²6

\begin{tabular}{|c|c|c|c|c|c|c|c|c|c|c|c|c|c|}
\hline & \multicolumn{7}{|c|}{ Governador } & \multicolumn{6}{|c|}{ Senado } \\
\hline & 1982 & 1986 & 1990 & 1994 & 1998 & 2002 & 2006 & 1982 & 1990 & 1994 & 1998 & 2002 & 2006 \\
\hline RO & & 2,93 & 5,02 & 2,91 & 3,51 & 5,07 & 2,63 & 2,08 & 1,00 & 3,36 & 3,65 & 6,53 & 3,41 \\
\hline$A C$ & 43 & 1,96 & 4,02 & 2,82 & 2,36 & 1,93 & 2,38 & 2,40 & 4,36 & 29 & 2,52 & 4,66 & 1,25 \\
\hline AM & 08 & 2,12 & 2,18 & 2,07 & 2,05 & 2,74 & 2,14 & 2,08 & 2,15 & 5,28 & 2,12 & 4,32 & 3,16 \\
\hline RR & & & 2,99 & 3,08 & 2,51 & 2,09 & 2,06 & & 2,90 & 3,40 & 3,76 & 4,64 & 2,07 \\
\hline PA & 07 & 2,13 & 2,72 & 3,12 & 2,78 & 3,63 & 2,82 & 2,07 & 3,30 & 5,20 & 3,06 & 5,21 & 2,54 \\
\hline AP & & & 3,33 & 2,76 & 2,87 & 3,68 & 2,31 & & 6,84 & 6,09 & 2,18 & 4,87 & 2,08 \\
\hline TO & & & 55 & 2,08 & 2,03 & 2,07 & 2,06 & & 1,00 & 4,82 & 1,68 & 2,28 & 2,18 \\
\hline MA &, 58 & 1,46 & 2,70 & 2,79 & 1,96 & 2,25 & 2,76 & 1,54 & 2,21 & 2,55 & 2,24 & 2,40 & 3,04 \\
\hline $\mathrm{PI}$ & 1,97 & 2,10 & 2,25 & 2,74 & 2,68 & 2,20 & 2,18 & 1,93 & 1,00 & 2,51 & 4,25 & 4,23 & 2,05 \\
\hline CE & 1,73 & 1,99 & 2,28 & 2,23 & 2,17 & 2,87 & 1,98 & 1,73 & 2,29 & 4,90 & 2,04 & 4,21 & 2,07 \\
\hline RN & 1,97 & 2,05 & 2,51 & 2,32 & 2,34 & 3,46 & 2,07 & 1,96 & 1,00 & 3,23 & 2,46 & 3,87 & 2,53 \\
\hline PB & 1,96 & 1,94 & 2,74 & 2,44 & 1,48 & 2,51 & 2,06 & 1,94 & 2,40 & 2,67 & 2,92 & 2,58 & 2,35 \\
\hline PE & 2,02 & 1,91 & 2,17 & 2,47 & 2,05 & 2,07 & 3,01 & 2,01 & 1,00 & 3,79 & 2,16 & 4,25 & 2,45 \\
\hline$A L$ & 1,98 & 2,14 & 2,03 & 1,54 & 2,01 & 2,25 & 2,42 & 1,97 & 1,00 & 4,68 & 2,21 & 2,91 & 2,73 \\
\hline SE & 58 & 2,12 & 1,65 & 2,21 & 3 & 2,96 & 2,09 & 1,58 & 2,01 & 39 & 2,44 & 6,54 & 1 \\
\hline $\mathrm{B}$ & 1,94 & 1,85 & 2,26 & 2,99 & 1,89 & 2,28 & 2,15 & 1,94 & 2,96 & 2,72 & 1,76 & 2,50 & 2,69 \\
\hline MG & 2,09 & 2,44 & 4,17 & 3,04 & 2,71 & 2,31 & 1,56 & 1,92 & 1,00 & 7,89 & 2,46 & 5,08 & 2,18 \\
\hline ES & 1,96 & 2,32 & 2,89 & 3,07 & 2,37 & 2,15 & 1,55 & 1,99 & 3,70 & 4,80 & 1,95 & 4,14 & 1,93 \\
\hline RJ & 3,72 & 2,44 & 2,33 & 3,77 & 2,77 & 2,84 & 3,68 & 3,71 & 2,45 & 6,40 & 3,48 & 5,43 & 2,78 \\
\hline SP & 2,97 & 3,46 & 3,26 & 3,29 & 4,20 & 3,34 & 2,28 & 2,98 & 1,01 & 5,40 & 2,90 & 5,26 & 2,37 \\
\hline PR & 1,99 & 1,77 & 3,36 & 2,22 & 2,07 & 4,37 & 2,88 & 1,99 & 1,00 & 4,61 & 2,03 & 4,42 & 2,18 \\
\hline SC & 2,03 & 2,74 & 2,78 & 2,89 & 2,35 & 3,08 & 2,72 & 2,03 & 2,18 & 4,21 & 2,89 & 4,54 & 2,32 \\
\hline RS & 2,95 & 3,05 & 3,41 & 2,68 & 2,33 & 3,05 & 3,8 & 2,94 & 3,10 & 4,60 & 2,49 & 4,08 & 4,12 \\
\hline MS & 2,08 & 1,97 & 2,19 & 2,44 & 3,02 & 2,40 & 1,92 & 2,07 & 1,00 & 4,91 & 2,57 & 3,72 & 2,24 \\
\hline MT & 2,02 & 1,92 & 2,06 & 1,75 & 2,27 & 2,64 & 2,08 & 2,01 & 2,28 & 4,40 & 2,37 & 4,72 & 2,27 \\
\hline GO & 1,81 & 2,22 & 2,28 & 3,25 & 2,19 & 2,55 & 2,45 & 1,83 & 2,43 & 2,68 & 1,88 & 3,84 & 1,63 \\
\hline DF & & & 2,64 & 2,97 & 2,72 & 2,76 & 2,8 & & 2,82 & 3,98 & 2,61 & 4,64 & 2,2 \\
\hline
\end{tabular}

Fonte: Bohn \& Paiva, 2006.

26 Para o senado não foi possível obter os dados para as eleições de 1986. 
Esses dados permitem afirmar que, em que pese os padrões diferentes verificados nas eleições majoritárias e proporcionais, existe também uma diversidade entre os estados. No entanto, há uma clara diferença entre o número de partidos nominais e partidos efetivos. O último é menor, o que permite afirmar que grande parte dos partidos que integram o Quadro 1 são irrelevantes para a competição política. Esse aspecto se torna mais interessante se considerarmos que uma das críticas feitas ao sistema partidário brasileiro é seu alto nível de fragmentação. Os dados apresentados por este estudo indicam que ao nível dos estados o sistema não é tão fragmentado como as visões pessimistas sobre o sistema partidário brasileiro preconizam.

O indicador utilizado - NEP - não permite distinguir o lugar de cada um dos partidos na competição eleitoral. Porém, dispomos de dados que nos permitem afirmar que PMDB, PT, DEM, PSDB, PP, PDT e PTB têm conquistado, entre 1982. 2006, a maioria expressiva dos votos nas eleições para a Câmara de Deputados (82,6\%), Assembléias Legislativas (78,4\%), Governador $(91,1 \%)$ e Senador $(83,6 \%)$, sendo, portanto, os partidos mais bem sucedidos no mercado eleitoral ${ }^{27}$. Assim, em relação ao formato do sistema partidário, os resultados deste artigo permitem afirmar a existência de um sistema multipartidário moderado. Um desdobramento deste estudo seria verificar o processo de nacionalização do sistema partidário a partir do desempenho dos partidos mencionados nas unidades da federação.

\section{Oferta Partidária e Eleitorado}

Nesta seção, tratamos da relação entre o amplo cardápio de opções partidárias colocadas à disposição do eleitorado e os padrões de apoio/rejeição ao mesmo. Em resumo, analisamos como os eleitores avaliam os partidos políticos brasileiros e o seu grau de representatividade. Alguns estudos têm chamado a atenção para o baixo grau de confiança desfrutado pelos partidos entre parcelas majoritárias do eleitorado (CARREIRÃO e KINZO, 2004; PAIVA, BRAGA e PIMENTEL, 2007). Nossa intenção é verificar se essa tendência tem se mantido ou não, com base nos resultados do LAPOP (Latin America Public Opinion Project) Brasil 2007.

O exame da Figura 1 mostra uma distribuição bastante concentrada de respostas e reduzida variabilidade, indicando que os entrevistados não apresentam índices expressivos em termo de representatividade dos partidos. As exceções são PSDB, PMDB e PT, que apresentam um patamar um pouco mais elevado do que os demais, com destaque para o PT, o qual se distancia em termos de

\footnotetext{
${ }^{27}$ Esses percentuais foram calculados a partir de informações disponíveis no seguinte banco de dados:
} < http://jaironicolau.iuperj.br/banco2004.html> Acesso em: maio 2008. 
FERREIRA, D. P., BATISTA, C. M., STABILE, M. A evolução do sistema partidário...

representatividade do pensamento do eleitor. Estes resultados também foram apresentados por Paiva, Braga e Pimentel (2007).

Figura 1 - Qual o partido que melhor representa a maneira como o(a) Sr(a) pensa?

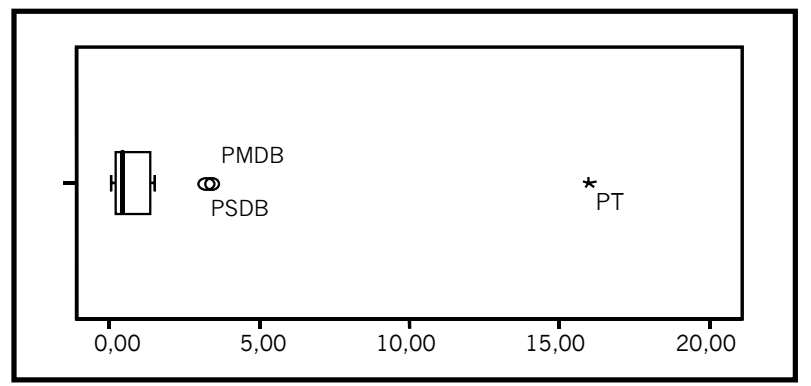

Fonte: LAPOP-Brasil, 2007.

Em relação à Figura 2, vemos que a distribuição dos resultados é relativamente simétrica, com pequena dispersão de repostas. O PT é o único partido situado completamente fora da distribuição, indicando que somente essa agremiação se destaca na recusa de votação em seus candidatos. Esse dado é interessante se confrontado com o resultado do boxplot anterior no qual o mesmo partido destaca-se pela maior representatividade do ponto de vista dos entrevistados. Desse modo, pode-se concluir que o partido destoa dos demais ao polarizar o eleitorado em termos de avaliações positivas ou negativas. Esse é um dado interessante a ser investigado em estudos sobre decisão eleitoral e seu impacto, por exemplo, sobre o voto estratégico.

Figura 2 - Qual o partido em que o sr./sra não votaria nos candidatos de jeito nenhum?

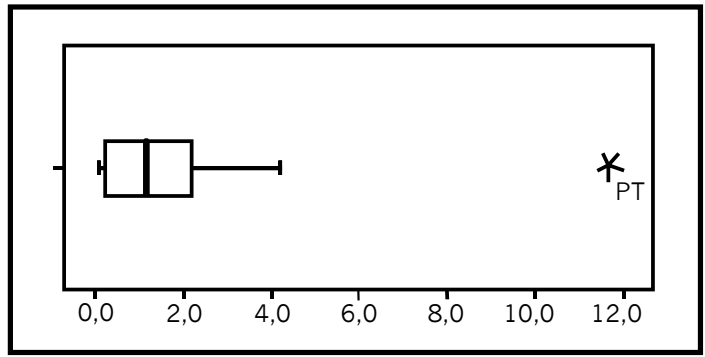

Fonte: LAPOP-Brasil, 2007. 
Em relação ao gosto partidário, novamente vemos uma distribuição com reduzida variabilidade. Portanto, não há um padrão de preferência pelos partidos políticos. No entanto, novamente se destacam PSDB, PMDB e, particularmente, o PT, que se distingue claramente com um valor excepcional da distribuição. Mais uma vez, para o bem ou para o mal, o partido se destaca (Figura 3).

Figura 3 - Há algum partido que o(a) Sr(a) goste mesmo que seja um pouquinho?Qual?

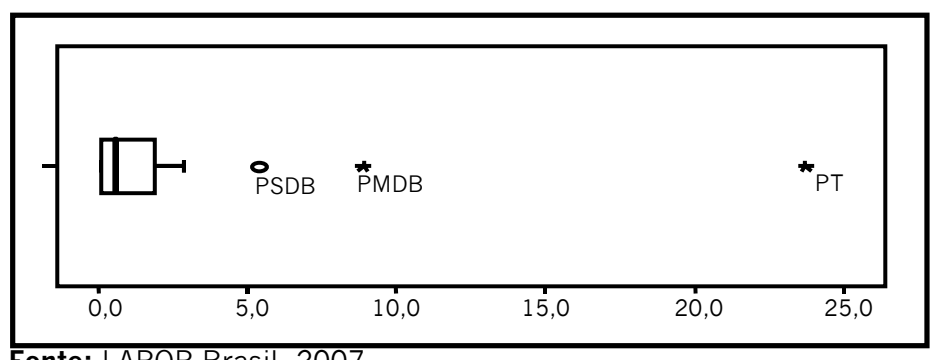

Fonte: LAPOP-Brasil, 2007.

Por sua vez, os dados comparativos da Tabela 4 permitem afirmar que os partidos políticos não desfrutam de grande simpatia por parte do eleitorado. Entre 2002 e 2006, houve um crescimento considerável da porcentagem de respostas "não" à pergunta: "O senhor gosta de algum partido político?", índice que se manteve praticamente o mesmo no ano seguinte. Logo, o gosto pelos partidos mostra uma tendência declinante e, em conseqüencia, seu antípoda tem uma trajetória de ascensão.

Tabela 4 - Gosto Partidário no Brasil

\begin{tabular}{|l|c|c|c|}
\cline { 2 - 4 } \multicolumn{1}{c|}{} & \multicolumn{3}{c|}{ O sr/sra gosta de algum partido político? } \\
\cline { 2 - 4 } \multicolumn{1}{c|}{} & ESEB 2002 & ESEB 2006 & LAPOP Brasil 2007 \\
\hline Não & 50 & 64 & 65 \\
\hline Sim & 48 & 33 & 30 \\
\hline NS/NR & 2 & 3 & 4 \\
\hline
\end{tabular}

Fonte: ESEB 2002, 2006 e LAPOP.Brasil, 2007.

A exemplo de estudos já mencionados, nossos dados evidenciam que os vínculos entre o eleitorado e os partidos são muito tênues e que o grau de representatividade dos últimos também é bastante baixo. Esses resultados não são 
FERREIRA, D. P., BATISTA, C. M., STABILE, M. A evolução do sistema partidário...

alentadores para a institucionalização dos partidos políticos brasileiros; entretanto, eles não permitem avaliar as causas desse fenômeno bem como em que medida os fatores socioeconômicos atuam nos graus de maior ou menor avaliação satisfatória das organizações partidárias.

É importante mencionar que os estudos de opinião pública têm revelado um baixo grau de confiança nas instituições e, de maneira paradoxal, altas taxas de adesão à democracia, chegando a 63,8 \% no LAPOP Brasil 2007. Nesse cenário, os partidos políticos, dificilmente, teriam uma avaliação diferente das demais instituições.

\section{Considerações Finais}

Os achados deste artigo permitem afirmar que, apesar da explosão da oferta eleitoral, observada no início do período analisado, o sistema partidário tem se mantido estável a partir dos anos noventa. Além disso, não é tão fragmentado e errático como se imagina à primeira vista. O grande número partidos nominais existentes em todo o período não reflete a dinâmica partidária, de forma acurada, fato verificado quando examinamos o NEP, não obstante em alguns estados esse indicador também tenha se mostrado elevado. Esses resultados indicam que os partidos têm cumprido a contento uma de principais suas tarefas, qual seja, estruturar a competição política na arena eleitoral. Ademais, é importante notar que as agremiações mais bem sucedidas nas urnas são também os mais longevos e que desfrutam de certo grau de representatividade.

Outro elemento a ser agregado é a tendência geral e contínua de declínio das taxas de volatilidade eleitoral, nos diferentes pleitos e em eleições consecutivas, como mostram Bohn e Paiva $(2006,2007)$. A volatilidade eleitoral tem sido um dos indicadores utilizados pela literatura para aferir o grau de institucionalização dos partidos e dos sistemas partidários, pois reflete a capacidade dos partidos de estruturar as escolhas do eleitorado (PRZEWORKSKI, 1975; PEDERSEN, 1980; MAINWARING e ZOCO, 2006).

Acompanhando a bibliografia citada neste artigo, podemos falar em um processo de consolidação do quadro partidário brasileiro. Contudo, quanto à representatividade e à avaliação por parte do eleitorado, os resultados não têm sido satisfatórios. Um desdobramento deste estudo é verificar a ação de outros mecanismos utilizados pelos partidos que possam nos ajudar a compreender melhor o que parece ser um paradoxo, por exemplo, a atuação das máquinas partidárias e estudos sobre decisão eleitoral. 


\section{Referências Bibliográficas}

BARDI, L. e MAIR, P."The Parameters of Party Systems". Party Politics, vol.14, n², 2008.

BOHN, S. e PAIVA, D. Política estadual e regional e volatilidade eleitoral no Brasil, Paper apresentado no Relatório Final de Pesquisa do Projeto "Bases Socioeconômicas da Volatilidade Eleitoral no Brasil", Processo No. 401912/2004-3 Edital No. 032/2004, CNPq, 2006.

Sistema Partidário de Volatilidade Eleitoral no Brasil: um estudo sobre a dinâmica inter-regional. Trabalho apresentado no 31ํㅡ. Encontro Anual da ANPOCS, 2007.

BRAGA, M. S. S. O processo partidário- eleitoral brasileiro: padrões de competição política 1982-2002. São Paulo: Universidade de São Paulo, (tese de doutorado/Ciência Política.), São Paulo: Associação Editorial Humanitas/FAPESP, 2006.

CARREIRÃO, Y. de S. e KINZO, M. D. G. "Partidos políticos, preferência partidária e decisão eleitoral no Brasil (1989-2002)". Dados, n47, 2004.

FERREIRA, D. P. Oposição e Transição Democrática: a estratégia peemedebista. Dissertação de mestrado apresentada ao Programa de Pós-Graduação em Ciência Política da UFRGS, 1990.

PFL X PMDB: Marchas e Contramarchas. Goiânia: Ed. Alternativa, 2002.

FLEISCHER, D. "Sistema Partidário Brasileiro: 1945-1997". Política Comparada, vol.1, n², 1997.

KINZO, M. D. G. Oposição e Autoritarismo: gênese e trajetória do MDB (1966-1979). São Paulo: Vértice, 1988. Adenauer, 1993.

. Radiografia do Quadro Partidário Brasileiro. São Paulo: Fundação Konrad

transição". São Paulo em Perspectiva, vol.14, n4, 2001.

. "Os Partidos no Eleitorado: percepções públicas e laços partidários no Brasil". Revista Brasileira de Ciências Sociais, vol.20, n57, 2005. 
KINZO, M. D. G. e BRAGA, M. S. S. Eleitores e Representação Partidária no Brasil. São Paulo: Humanitas/Fapesp, 2007.

KINZO, M. D. G. e SILVA, S. R. PMDB. São Paulo: Fundação Konrad-Adenauer-Stiftung, 1996.

KORNBLITH, M. Situación y Perspectivas de los Partidos en La Región Andina: caso Venezuela. In: Seminário Regional: Situación actual de los partidos en La Región Andina. Estocolmo: IDEA, 2004.

KRAUSE, S. e PAIVA, D. Perdas e Ganhos. Lideranças políticas brasileiras e instabilidade na representação dos partidos: lógica nacional X lógica estadual (1982-2001)". In: PINTO, C. R. e SANTOS, A. M. (orgs). Partidos no Cone Sul: Novos Ângulos de Pesquisa. Rio de Janeiro: Fundação Konrad-Adenauer, 2002.

LAAKSO, M. e TAAGEPERA, R. "Effective Number of Parties: a measure with application to Western Europe". Comparative Political Studies, vol.12, n¹, 1979.

LAMOUNIER, B. O "Brasil Autoritário" revisitado: o impacto das eleições sobre a abertura. In: STEPAN, A. (org.). Democratizando o Brasil. Rio de Janeiro: Paz e Terra, 1988.

De Geisel a Collor: o balanço da transição. São Paulo:Idesp/Sumaré, 1990.

LIMA JR., O. B. Partidos políticos brasileiros: a experiência federal e regional 1945-64. Rio de Janeiro: Edições Graal, 1983.

(org.). O sistema partidário brasileiro: diversidades e tendências (1982-1994). Rio de Janeiro: Ed. FGV, 1997.

LIMONGI, F. e FIGUEIREDO, A. "Partidos Políticos na Câmara dos Deputados". Dados, vol.38, n³, IUPERJ, 1995.

1999.

. Executivo e Legislativo na Nova Ordem Constitucional. Rio de Janeiro: Ed. FGV,

MAINWARING, S. Rethinking Party Systems in the Third Wave of Democratization: The Case of Brazil. Stanford: Stanford University Press, 1999. 
MAINWARING, S. e SCULLY, T. Building Democratic Institutions: party systems in Latin America. Stanford: Stanford University Press, 1995.

MAINWARING, S. e TORCAL, M. Party System Institutionalization and party system theory after the Third Wave of Democratization. In: KATZ, R. \& CROTTY, W. (eds.). Handbook of Political Parties. London: Sage Publications, 2006.

MAINWARING, S. e ZOCO, E. "Political sequences and the stabilization of interparty competition: electoral volatility in old and new democracies". Party Politics, vol.13, n², 2006.

MELO, C. R. F. Retirando as Cadeiras do Lugar: Migração Partidária na Câmara dos Deputados (1985/2002). Belo Horizonte: Editora UFMG, 2004.

MENEGUELLO, R. Partidos e Governos No Brasil Contemporâneo (1985-1997). São Paulo: Paz e Terra, 1998.

NICOLAU, J. M. Multipartidarismo e Democracia: Um Estudo Sobre O Sistema Partidário Brasileiro (1985-94). Rio de Janeiro: Ed. FGV, 1996.

PAIVA, D. ,BRAGA. M. S. S. e PIMENTEL, J. "Eleitorado e Partidos Políticos no Brasil". Opinião Pública, vol.13, n², 2007.

PEDERSEN, M. N. "On measuring party system change. A methodological critique and a suggestion”. Comparative Political Studies, vol.12, n4, 1980.

PRZEWORSKI, A. "Institutionalization of voting patterns, or is it mobilization of the source of decay?". American Political Science Review, vol.69, 1975.

RODRIGUES, L. M. Partidos, Ideologia e Composição Social. São Paulo: Edusp, 2002.

ROSE, R, e MACKIE, T. T. Do Parties Persist to Fail? The Big Trade-off Facing Organization. In: LAWSON, K. e MERKL, P. When Parties Fail: Emerging Alternative Organizations. Princeton: Princeton University Press, 1988.

SANTOS, F. (org). O poder legislativo nos estados: identidade e convergência. São Paulo: Ed. FGV, 2001. 
. "Brazilian Democracy and the Power of "Old" Theories of Party Competition". Brazilian Political Science Review, vol.1, n², 2008.

SARTORI, G. Partidos e Sistemas Partidários. Brasília: Ed. UnB, 1982.

SCHMITT, R. Partidos Políticos no Brasil (1945-2000). Rio de Janeiro: Jorge Zahar Editor, 2000.

SOARES, G. A. D. Sociedade e Política no Brasil. São Paulo: Difel, 1973.

. A Democracia Interrompida. Rio de Janeiro: FGV, 2001.

STEPAN, A. (org.). Democratizando o Brasil. Rio de Janeiro: Paz e Terra, 1988.

WARE, A. Political Parties and Party Systems. New York: Oxford University Press, 1996.

TSE: <www.tse.gov.br>

Denise Paiva Ferreira · denise@fchf.ufg.br

Carlos Marcos Batista - carlosbatista@unb.br

Max Stabile·me@maxstabile.com

Recebido e aprovado para publicação em agosto de 2008. 